\title{
Acercar-se da morte: a correspondência entre Hermann Broch e Egon Vietta
}

\author{
Daniel Reizinger Bonomo ${ }^{1}$
}

BROCH, Hermann/VIETTA, Egon. "Sich an den Tod heranpürschen..." Hermann Broch und Egon Vietta im Briefwechsel 1933-1951. Organização de Silvio Vietta e Roberto Rizzo. Göttingen: Wallstein, 2012.

Hermann Broch, pensador e poeta entre os mais destacados da língua alemã, tem sua introdução no mundo lusófono apenas iniciada: contamos com a tradução de seus romances mais importantes, ${ }^{2}$ mas a parcela teórica de sua obra permanece quase tão desconhecida quanto sua dramaturgia ou lírica. ${ }^{3}$ No entanto, a recente circulação em livrarias brasileiras de seus dois romances mais comentados, Os sonâmbulos e A morte de Virgílio, ${ }^{4}$ permite supor a existência de um interesse crescente, ainda que tímido, em sua obra. Nesse sentido, vale recordar que permanece igualmente desconhecido das traduções em língua portuguesa seu epistolário, que compõe, nos últimos tempos, os mais instigantes volumes da bibliografia brochiana.

A primeira publicação de um conjunto de cartas de Broch recua à primeira edição de sua obra reunida, organizada para a editora Rhein, em 1957. Em 1971, viria à luz, em edição caprichada, a correspondência com Daniel Brody, que, à frente da editora Rhein, havia publicado, na passagem para a década de 1930, Os sonâmbulos. A verdadeira contribuição, porém, para o conhecimento de sua atividade epistolar seria a

\footnotetext{
${ }^{1}$ Doutor em Língua e Literatura Alemã pela Faculdade de Filosofia, Letras e Ciências Humanas da Universidade de São Paulo. E-mail: drbonomo@gmail.com

${ }^{2}$ Em língua portuguesa, no que respeita à obra romanesca de Broch, temos publicados Os sonâmbulos, traduções de António Ferreira Marques e Jorge Camacho em Portugal (1988-89) e de Marcelo Backes no Brasil (2011); A morte de Virgílio, traduções de Herbert Caro no Brasil (1982) e de Maria Adélia Silva Melo em Portugal; $O$ encantamento, tradução brasileira de Lya Luft (1990); e Os inocentes, tradução brasileira de Herbert Caro (1988).

${ }^{3}$ As primeiras traduções de sua obra teórica surgem com nosso doutoramento (2008-2012), que inclui versões em língua portuguesa de dois ensaios de Broch, "James Joyce e o presente" e "A mundivisão do romance", acrescentados de seus comentários aos Sonâmbulos. Cf. BONOMO, Daniel R. "Impaciência do conhecimento". Aproximações aos Sonâmbulos de Hermann Broch. Tese de doutorado. FFLCH/USP, São Paulo, 2012.

${ }^{4}$ O selo Benvirá, de São Paulo, editou Os sonâmbulos em 2011 e A morte de Virgílio em 2013.
} 
publicação dos três volumes que concluem a reunião de sua obra (em 17 volumes) levada a cabo e comentada por Paul Michael Lützeler, para a editora Suhrkamp, entre 1974 e 1981. Lützeler organizaria ainda, para a mesma editora, a correspondência de Broch com Volkmar von ZüHLSDORFF (1986), com Hannah ARENDT (1996), e o volume com as missivas à amante Ea von ALLESCH (1998), redigidas, como diário, em 1920. Nos últimos anos, completariam essas iniciativas as compilações em volume de sua correspondência com a última companheira, Annemarie MEIER-GrAEFE (2001), com o escritor e historiador H. G. AdLER (2004), com Ruth NORDEN (2005), com o psicanalista, discípulo de Freud, Paul FEDERN (2007), com Ernst SCHÖNWIESE (2008), com o filho ARMAND (2010) e com o escritor e sociólogo Erich von KAHLER (2010).

Agora, organizadas por Silvio Vietta e Roberto Rizzo, publicam-se as cartas trocadas entre Hermann Broch e Egon Vietta. Trata-se de uma coleção de 83 documentos, a maioria assinada por Broch, compreendendo aproximadamente duas décadas de conversa. Os organizadores foram cuidadosos: adicionando comentários, incluindo textos pouco acessíveis de Vietta sobre Broch e um posfácio bastante completo, arranjaram uma edição cuja qualidade é digna de nota. Fazem, assim, devida justiça à importância dessas cartas, cujo significado aliás não diz respeito somente à vida e obra de Broch.

Nascido em Bühl (Baden), Alemanha, em 1903, Egon Vietta escreveu seus primeiros ensaios e tentativas literárias na segunda metade da década de 1920. Seus interesses foram amplos e variados, mas têm em comum os domínios literário e artístico, político e filosófico. No literário, redigiu um estudo sobre Georg Trakl, ensaios, peças de teatro e romances; dedicou-se igualmente a livros de viagens, relatando, por exemplo, suas experiências no Norte de África; no político, durante a Segunda Guerra Mundial, juntou-se ao grupo de opositores de Hamburgo; no filosófico, escreveu sobre Martin Heidegger e a filosofia francesa contemporânea. Além disso, estabeleceu uma correspondência não apenas com Broch, mas com Gottfried Benn e o mesmo Heidegger. Após 1945, contribuiu com publicações para diversos periódicos e também desacreditou, de certa maneira, os rumos europeus do pós-guerra, como atestam seus últimos livros. ${ }^{5}$ Morreu em 1959, em Baden-Baden, oito anos após Broch.

\footnotetext{
5 A respeito disso, os organizadores mencionam os títulos Wende oder Katastrophe des Deutschen Theaters (1955) e Europa ist in Asien gebettet (1955), o primeiro crítico do teatro alemão contemporâneo e o segundo testemunha de uma última viagem de Vietta.
}

Pandaemonium, São Paulo, v. 16, n. 22, Dez/2013, p. 339-343 
Bonomo, D. R. - Acercar-se da morte

A correspondência entre Broch e Vietta, da maneira como foi preservada, inicia em agosto de 1933. A princípio, leem-se apenas as cartas de Broch, visto que os documentos mais antigos assinados por Vietta já não existem. Foram possivelmente destruídos pelo próprio Broch em seus últimos dias austríacos, quando, ao fugir dos nazistas, levou consigo apenas uma parcela de seus manuscritos. É concebível, portanto, que tenha destruído as cartas de Vietta a fim de não comprometer, com sua fuga, o amigo que fica. Assim, o diálogo, nesta edição, começa propriamente em 1946, ano da primeira carta conservada de Vietta, prosseguindo sem maior intervalo até a morte de Broch. A última carta de Broch a Vietta data de abril de 1951. Broch morre no mês seguinte.

A morte, além disso, é tema recorrente da correspondência. O título dado à edição é frase de Broch ("sich tunlichst an den Tod selber heranzupürschen, da [sich] das Wesen des Dichterischen, also auch das Vergils bloss von der Todesvorstellung aus erklären lässt") e faz referência a seu trabalho na Morte de Virgílio. Esse romance, exemplar das experiências mais difíceis do gênero, "dos mais incomuns e fundamentais experimentos já realizados com o meio flexível do romance" (Thomas Mann), deve-se, diz Broch, à convivência com a morte, sua ameaça e presença. Na passagem, que intitula a correspondência e é trecho de carta de fevereiro de 1938, o romancista relata o surgimento da obra nos seguintes termos: a partir de um "esboço" feito para leitura radiofônica surgiu a necessidade de aproximar-se, neste movimento sorrateiro, de espreita e caça (pirschen), da morte; diz que a poesia, essencialmente - e assim também seu romance -, só se deixa explicar com a imaginação e representação da morte; diz não ter vivido um transe ou um sonho, pois teria de construir essa vivência, o que "sempre evita", 6 mas que, "ainda assim", possuía duas centenas de páginas prontas, aparecidas de certa forma "sem" sua vontade, "contra" sua vontade, e certamente contrárias à vontade de seu editor e a sua própria situação financeira. Aqui, os termos de Broch, se desvelam alguma ironia com a menção às páginas aparecidas "ainda assim”, se repetem, igualmente, a célebre condição de poeta "à revelia" (divulgada especialmente por Hannah Arendt), sem dúvida não fazem pouco caso do que chama de "necessidade" e tampouco desmerecem a dificuldade da redação. Fala, por exemplo, da complicação do estudo da matéria histórica, exigido pela configuração de seu romance, que remonta ao

\footnotetext{
${ }^{6}$ Posteriormente, porém, tratando da redação do romance, refere-se a "estados oníricos de transe" (carta de setembro de 1947), problematizando sua afirmação primeira.
}

Pandaemonium, São Paulo, v. 16, n. 22, Dez/2013, p. 339-343 
tempo de Augusto; e fala, noutro lugar da correspondência, como renunciou a todo tipo de convenção e como talvez fosse melhor não ver publicada A morte de Virgílio, uma vez que transformar em arte sua vivência da morte era de certo modo se afastar dela.

O Virgílio não é o único tema das cartas. As cartas de Broch distinguem mais assuntos conhecidos de seu pensamento, como as relações entre mito e história, poesia, religião e filosofia. Mas, a bem da verdade, mesmo que não seja objeto central da correspondência, o momento não permite ignorar a situação de artistas e intelectuais na conjuntura do regime nacional-socialista e após seu arruinamento. Aí, os organizadores da edição notam que Broch antecipa o debate iniciado por Adorno acerca do barbarismo da poesia depois de Auschwitz. Em carta de novembro de 1947, Broch comenta que o “elemento lúdico da obra de arte é inadmissível em tempos de câmaras de gás", acrescentando: se A morte de Virgílio estivesse condicionada a uma experiência dessa natureza, seria um "sacrilégio" simplesmente a transformar em romance. A questão é complexa, seja no que respeita aos significados do romance de Broch, seja no que aponta para quadro mais amplo. Já na fase dos Sonâmbulos, eram preocupações constantes de Broch a possibilidade e a legitimação da poesia num mundo em destroços; no ensaio que consagrou a Joyce, publicado em 1936, falava, por exemplo, da “impossibilidade de expressão de um mundo condenado ao mutismo".

Broch, além disso, exilado desde 1938, tem no interlocutor Vietta, que permaneceu na Alemanha, um contrapeso à imagem dos escritores expatriados. Afirma, em determinado contexto, que "inveja" a resistência in loco de Vietta, pois, com exceção do período encarcerado e da fuga arriscada, não teria experimentado "as coisas essenciais" da violência nazista. Nesse sentido, a posição de Broch, sem fazer tábua rasa do passado recente, é diversa da de Thomas Mann, que, também exilado, pronunciou-se em carta aberta contra aqueles que ficaram em território hitlerista, expondo, então, as razões "por que não retornava à Alemanha". Vietta, em carta de janeiro de 1946, referese à resposta de Frank Thiess - à época nome assinalado da literatura alemã - a Mann, em que se lê grave recusa às acusações deste. Mann, nessa carta aberta, incita boa polêmica ao qualificar os livros que puderam ser publicados na Alemanha entre $1933 \mathrm{e}$ 1945 de "menos que nulidades". O juízo, tomado à letra, não pouparia nomes como os dos próprios Frank Thiess e Egon Vietta. E por certo não excluiria nomes como o de Heidegger, cuja atitude, à diferença das de Thiess e Vietta, que, apesar da proximidade, se indispuseram com a ideologia nazista, não era simplesmente desculpável. 
Bonomo, D. R. - Acercar-se da morte

Mas as relações são sempre mais difíceis, como o pensamento e a importância de Heidegger, que, por isso mesmo, surge repetidamente na correspondência. É já comentado na primeira carta do volume e parece atar um laço fundamental entre Broch e Vietta. Nessa carta, Broch procura, em resumo, formular o que separa sua "teoria do valor" do pensamento de Heidegger e assinalar o que ambos têm em comum, por exemplo, com Kierkegaard. Com relação à mancha em tempos nebulosos, Broch, em carta de abril de 1946, dá notícia da má reputação do filósofo nos Estados Unidos: diz que não é visto exatamente como um "antifascista", que não será facilmente perdoado pelo que fez com Husserl, ${ }^{7}$ que suas aulas sobre Nietzsche foram entendidas como um protesto fraco e que seus livros tiveram reedições durante esse período. "É lamentável", diz ainda Broch, pois fala "de um dos temperamentos filosóficos mais fortes desta época, talvez o mais forte". Em momento algum, pois, a censura é descomplicada. Dois anos depois, início de 1948, lendo o texto de Heidegger sobre Hölderlin, Broch já pensa no significado "pós-nazista" do filósofo. E, pouco antes de morrer, as palavras finais dirigidas a Vietta parecem gostar de saber e informar ao amigo que Heidegger, via Hannah Arendt, ${ }^{8}$ perguntava pelos Inocentes, último romance de Broch, em que estuda, magistral e justamente, este envolvimento dúbio com o mal de cada dia. Mas infelizmente não sabemos se Heidegger os leu, tampouco arriscamos supor, de improviso, o que teria pensado. É interessante afinal que alguns nós não sejam desatados. E são vantagens da correspondência entre Broch e Vietta não limitar o interesse, não encerrar as conversas e não circunscrever sua pertinência à vida e obra dos correspondentes - por si só motivos suficientes para a leitura das cartas -, mas enriquecer o acervo dos documentos de uma época, apesar das tantas mortes, ainda viva.

recebido em 01/08/2013

aceito em 15/08/2013

\footnotetext{
${ }^{7}$ Broch, aqui, adere ao rumor de que Heidegger teria vetado a entrada de Husserl na biblioteca da Universidade de Freiburg. Segundo os organizadores, a relação de Heidegger com seu professor Husserl, na década de 1930, é ambivalente e não pode ser de todo esclarecida. Mencionam que Heidegger, entrevistado em 1976, diz que se trata de "calúnia" o episódio do veto. No entanto, notam que a edição de 1941 de Ser e tempo, à diferença de ediçoes anteriores e posteriores, vai publicada sem a dedicatória a Husserl.

${ }^{8}$ Heidegger, em carta a Hannah Arendt, pergunta propriamente a respeito de Broch, quer saber se há qualquer coisa nova. Arendt, por sua vez, menciona a remessa dos Inocentes a Heidegger.
}

Pandaemonium, São Paulo, v. 16, n. 22, Dez/2013, p. 339-343 